\title{
Chitosan-Based Materials for Wound Healing and Tissue Engineering: An Overview on their Properties and Applications
}

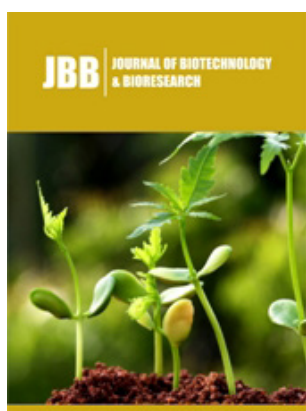

*Corresponding author: Mohammad Reza Kasaai, Department of Food Science and Technology, Sari Agricultural Sciences and Natural Resources University, Iran Mail ID: reza_kasaai@hotmail.com

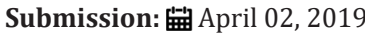

Published: 侮 May 22, 2019

Volume 2 - Issue 1

How to cite this article: Mohammad Reza Kasaai. Chitosan-Based Materials for Wound Healing and Tissue Engineering: An Overview on their Properties and Applications. J Biotech Biores.2(1). JBB.000526.2019.

Copyright@ Mohammad Reza Kasaai. Senejani, This article is distributed under the terms of the Creative Commons Attribution 4.0 International License, which permits unrestricted use and redistribution provided that the original author and source are credited.

\section{Mohammad Reza Kasaai*}

Department of Food Science and Technology, Sari Agricultural Sciences and Natural Resources University, Iran

\begin{abstract}
In this study, an effort has been made to provide a global view from some available literature information on properties and applications of chitosans for wound healing and tissue engineering. Renewable resources, Environmentally friendly, Biodegradability, Biocompatibility, Non-toxicity and Anti-microbial properties make chitosans as the most promising and interesting materials for medicine and health care applications. Chitosans and their some derivatives also exhibit film and fibre forming properties. Chitosans with Hydrophilic/ Hydrophobic nature provide a variety of surface functional groups to bind with bioactive compounds, and target organs of the human body, and consequently result in an increase in their stability. Hydrophilic/ Hydrophilic characters of the chitosans would yield in various possibilities and finally open several opportunities for various applications in medicine and health care sectors. Chitosan is a unique Biotechnological/ Biomaterial choice for wound healing and tissue engineering.
\end{abstract}

Keywords: Chitosan; Biotechnology; Health care; Wound healing; Tissue engineering

\section{Introduction}

Chitin and chitosan are natural polymers and classified as polysaccharides. The natural polymers are alternatives to synthetic polymers, in which they are derived from petroleum resources. Chitin and chitosan materials are the most rapidly growing part of polymer science and technology and biotechnology. They can be applied in four major industrial areas of biotechnology

A. Health care

B. Crop production and agriculture

C. Non-food industrial uses such as biodegradable plastics, vegetable oil, and biofuels

D. Environmental uses [1,2]

Chitosan plays important roles in biological phenomena and various processes [3]. Biotechnology is the broad area of biology and is based on the biological sciences (Molecular biology, Biochemistry, Cell biology, Embryology, Genetics, Microbiology), and provides methods to support and perform research and development in the laboratory and technological applications that uses biological systems [1,2]. Chitins and chitosans are widely used in artificial muscles and wound healing, due to their non-toxicity, biodegradability and biocompatibility $[4,5]$. In this article, an effort has been made to provide a global view from some available literature information on properties and applications of chitin and chitosans in wound healing and tissue engineering.

\section{Sources, Structure and Production}

Chitin similar to cellulose can be classified as structural polysaccharides. Next to cellulose, chitin is the second most abundant polysaccharides found in nature. Chitin occurs naturally as a support system in plants and animals, hard skeleton of shellfish and marine invertebrate (Crab, Shrimp, Lobster, Prawn Krill, Clams, Oysters and Squid) [6-9]. It is generally isolated from crustacean shells and is considered as a cellulose derivative. The chemical structure of chitin is like cellulose. The difference between chemical structure of cellulose and chitin is that the 2-Hydroxy groups of cellulose have been replaced with N-Acetyl groups, and results 
in Beta-(1-4)-2-Acetarnido-2-Deoxy-D-Glucopynnosic structural units (GlcNAc) [9]. Deacetylation of chitin results in chitosan, consists of $\beta(1 \rightarrow 4)$ linked D-Glucosamine residues [10-12]. Chitosans are used for both partially and completely deacetylated chitosans $[12,13]$. In the production of chitin, proteins, calcium carbonate, and pigments were separated from crustacean shells. Proteins, calcium chloride, and carotenoid pigments are side products obtained from isolation of chitin [12].

\section{Properties and Functions of Chitosans}

Chitosan is the only cationic polysaccharide. Its cationic nature in acidic medium is unique among polysaccharides. Chitosan is very sensitive to the presence of anionic substances in its solutions $[14,15]$. The ability of chitosan to bind with anionic compounds such as DNA is of great importance. The formation of chitosan-DNA complexes renders chitosan as a good support in orthopaedic gene therapy [16]. Chitosan and some of its derivatives exhibit film and fibre forming properties [17]. Chitosan with various anti-microbial properties, make it a good and qualified candidate in biomedical applications $[14,18,19]$. Chitin and chitosan also exhibit mucoadhesion and immune-stimulatory activities [20].

Various biological properties such as promoting wound healing, and the process-ability in a variety of different Macro and Nano-shapes makes chitosan as a prominent scaffold material for cartilage, intervertebral disc, and bone tissue substitutes. It is known to be important in cell proliferation and tissue regeneration $[21,22]$. Cell aggregates were observed in several inter-membrane spaces, showing that cells can be introduced and cultured within these new systems for tissue engineering [23]. Chitosan is a unique Biotechnological/ Biomaterial choice for tissue engineering. Chitosan was shown immune-potentiation and

wound-healing-promoting properties [24]. Chitin is not soluble in most common organic and inorganic solvents.

Deacetylation of chitin, introduction of hydroxyl or carboxyl groups into chitin results in an improvement in its solubility, which promotes processing, and thereby widening its practical applications [12]. Chitosan as a biopolymer has advantage over synthetic polymers due to its solubility in water $[25,26]$. One of the main physicochemical properties of a drug for development into clinical applications is the water solubility. In many cases, the drug solubility in water is not high enough to lead to in vivo therapeutic efficacy.

\section{Applications of Chitosans in Wound Healing and Tis- sue Engineering}

The properties and renewable resources make chitosan superior to synthetic polymers and particularly useful in medicine and health care $[16,18,20,24]$. Applications of chitosans in contrast to synthetic polymers, reduce both environmental harms and different risks of possible diseases for human life. Chitosans have been selected, where environmental issues and different risks of possible diseases have been taken into consideration. Active steps have been already taken to move chitin and chitosan research from the academic laboratory bench to practical medical applications. The biomedical applications of chitin and chitosans have been started since the late 1990s. Medical grade materials are now more available and chitosan-based biomedical products have been introduced.

The reconstruction of the periodontal tissue with chitosan were a prelude to the discovery of the osteo inductive properties of chitosan [27]. For burns a chitosan cream has been developed. For Surgery, chitosan suture thread will become available that is better biodegradable and or more uniform as compared to the available materials. Chitosan membranes for burn healing and chitosan bandage for lens surgery as being investigated that are Biocompatible, Biodegradable and transparent, that allow inspection of the healing process without removal. Coating of artificial limbs by chitosan look promising [28]. Oxy-chitin keeps the regenerative properties of chitin and chitosan. In a model study, surgical lesions in rat condyles were treated with $\mathrm{N}$, $\mathrm{N}$-Diacarboxymethyl chitosan or 6-Oxychitin sodium salt.

Morphological data indicate that the best osteo architectural reconstruction was promoted by 6-0xychitin, even though healing was slower compared to with $\mathrm{N}$, N-Diacarboxymethyl chitosan. Complete healing was obtained with N, N-Dicarboxymethyl chitosan within three weeks. 6-0xychitins of fungal and animal origins, in the form of free acids, salts and esters, might find applications as surrogates of hyaluronans and of bacterial antigens in medical and health care products [29,30]. Chitosan as an interested polymer has been used for encapsulation of drug components, because of its mucous adhesiveness, and other above-mentioned general properties of chitosans [31]. Tissue engineering utilizing chitosan to perform the scaffold function have been popular since this fields took off in the early 1990s.

Applications of chitosan in tissue engineering and wound healing have been reviewed [32-34]. Chitin and chitosan have been used extensively for wound healing. The interaction of chitin and chitosan with wound bed in promoting healing have been confirmed [35]. The haemostatic properties of chitosan are again highlighted, while the role played by chitin materials interacting with various factors and enzymes are elaborated. A discussion of various forms of chitin and chitosan containing gels and films and their role in cartilage repair, nerve regeneration, and other uses were also included. One area where focus of much work can be addressed is that of generating new forms especially hydrogels [36].

\section{Conclusion}

In this study, an effort has been made to provide a global view from some available literature information on properties, and applications of chitin and chitosan for wound healing and tissue engineering. Biocompatibility, and Biodegradability make chitosan an excellent candidate for health care applications. Chitin and chitosan with renewable resources without or with a low toxicity and antimicrobial properties are promising materials for various 
branches of biotechnology (food, nutrition, medical and health care) applications. Chitosan exhibits film and fibre forming properties. Chitosan can bind with negative charged materials via electrostatic interactions of opposite charges of human organs. Chitosan with anti-microbial properties has opened vast applications in different branches of medicine. It has been used as a shell for encapsulation of bioactive compounds, and drugs employed in different branches of medicine and as a scaffold in tissue engineering.

\section{Future Perspective}

A number of bioactive or biomedical products derived from chitin and chitosan, and useful for wound healing and tissue engineering have already entered or will enter in the market in the future. Investigation on the chitin and chitosan new area of research would result in a better quality of medical practices. Applications of natural materials respecting environment concerns to convert renewable wastes into value-added components offer a good opportunity to avoid further destruction and pollutions of this planet.

\section{References}

1. Arms K, Camp PS (1995) Biology (4 $4^{\text {th }}$ edn), Saunders College Publishing, Harcourt Brace College Publishers, New York, USA.

2. Raven PH, Johnson GB (2002) Biology (6 $6^{\text {th }}$ edn), McGraw-Hill, New York, USA.

3. Alger M (1999) Polymer Science Dictionary, Chapman \& Hall Publishing Company, CRC press, UK.

4. Kim HS, Kacew S, Lee BM (1999) In vitro chemopreventive effects of plant polysaccharides (Aloe barbadendis miller, Lentis edodes, Ganoderma lucidum and Coriolus versicolor). Carcinogenesis 20(8): 1637-1640.

5. Wang PY, Zhu XL, Lin ZB (2012) Antitumor and immunomodulatory effects of polysaccharides from broken spore of Ganoderma lucidum. Front Pharmacol 3: 135.

6. Alwarappan S, Cissel K, Dixit S, Mohapatra S, Li CZ (2012) Chitosanmodified grapheme electrodes for DNA mutation analysis. J Electroanal Chem (lausannne) 686: 69-72.

7. Blair HS, Guthrie J, Law T, Turkington P (1987) Chitosan and modified chitosan membranes I. Preparation and characterisation. Journal of Applied Polymer Science 33(2): 641-656.

8. Knorr D (1984) Use of chitinous polymers in food. A challenge for food research and development. Food Technology 38(1): 85-97.

9. McCormick CL, Bock J, Schulz DN (1989) Water-soluble polymers. In: Mark HM, Biksles N, Ovcrberger CG, Mrngrs G, Kroschwitz J (Eds.), Drcy Polymer Science and Engineering, John Wiley\& Sons, New York, USA, pp. 752-753.

10. Hudson SM, Smith C (1998) Polysaccharides: Chitin and Chitosan: Chemistry and technology of their use as structural materials. In: Kaplan DL (Ed.), Biopolymers from Renewable Resource, Springer-Verlag Berlin, USA, pp. 98-118.

11. Knaul JZ, Kasaai MR, Bui VT, Creber KAM (1998) Characterization of deacetylated chitosan and chitosan molecular weight review. Canadian Journal of Chemistry 76(11): 1699-1706.

12. Van Luyen D, Houng DM (1996) Chitin and derivatives. In: Salamone JC (Ed.), Polymeric Materials Encyclopedia 2, CRC Press, Boca Raton, USA, pp. 1208-1217.

13. Kasaai MR (2009) Various methods for determination of the degree of
N-acetylation of chitin and chitosan: A Review. J Agric Food chem 57(5): 1667-1676.

14. Sandford PA, Hutchings GP (1987) Chitosan-a natural, cationic biopolymer: Commercial applications in Industrial Polysaccharides, Genetic Engineering, Structure/Property Relations and Applications. In: Yalpani M (Ed.), Elesvier Science, Amsterdam, Netherland, pp. 363-375.

15. Sorlier P, Denuzie're A, Viton C, Domard A (2001) Relation between the degree of acetylation and the electrostatic properties of chitin and chitosan. Bio-macromolecules 2(3): 765-772.

16. Muzzarelli RAA (2011) Chitosan scaffolds for bone regeneration. In: Kim SK (Ed.), Chitin chitosan oligosaccharides and their derivatives: Biological Activities and Applications (Chapter 17), CRC Press: Taylor \& Francis Group, Boca Raton, USA, pp. 223-239.

17. Rathk TD, Hudson SM (1994) Review of chitin and chitosan as fibre and film formers. Journal of Macromolecular Science Part C 34(3): 375-437.

18. Allan GG, Altman LC, Bensinger RE, Ghosh DK, Hirabayashi Y, et al. (1984) Biomedical applications of chitin and chitosan in chitin chitosan and related enzymes. In: Zikakis JP (Ed.), Academic Press, New York, USA, pp. 119-133.

19. Elsabee MZ, Abdou ES (2013) Chitosan based edible films and coatings: A Review. Materials Science and Engineering 33(4): 1819-1841.

20. Jayakumar R, Menon D, Manzoor K, Naira SV, Tamura H (2010) Biomedical applications of chitin and chitosan-based nanomaterials: A short review. Carbohydrate Polymers 82(2): 227-232.

21. Boucard N, Vitona C, Agay D, Mari E, Roger T, et al. (2007) The use of physical hydrogels of chitosan for skin regeneration following thirddegree burns. Biomaterials 28(24): 3478-3488.

22. Montembault A, Tahiri K, Korwin ZIC, Chevalier X, Corvol MT, et al. (2006) A material decoy of biological media based on chitosan physical hydrogels: Applications to cartilage tissue engineering. Biochimie 88(5): 551-564.

23. Ladet S, David L, Domard A (2008) Multi-membrane hydrogels. Nature Letter 452: 76-79.

24. Koide SS (1998) Chitin-chitosan: Properties, benefits and risks. Nutrition Research 18(6): 1091-1101.

25. Anthonsen MW, Varum KM, Smidsrod O (1993) Solution properties of chitosans: Conformation and chain stiffness of chitosans with different degree of N-acetylation. Carbohydrate Polymers 22(3): 193-201.

26. Thanou M, Verhorf JC, Junginger HE (2001) Oral drug absorption enhancement by chitosan and its derivatives. Advanced Drug Delivery Reviews 52(2): 117-126.

27. Muzzarelli RAA, Biagini G, Pugnaloni A, Filippini O, Baldassarre V, et al. (1989) Reconstruction of paradontal tissue with chitosan. Biomaterials 10(9): 598-603.

28. Stevens WF (1996) Chitosan: A key compound in biology and bioprocess technology. In: Stevens WE, Rao MS, Chandrkrachang S (Eds.), Chitin and chitosan environmentally friendly and versatile biomaterials. The proceedings of the second Asia pacific symposium, Bioprocess Technology Program Asian Institute of Technology, Bangkok, Thailand, pp. 13-21.

29. Mattioli BM, Nicoli AN, De Beneditis A, Sgarbi G, Amati S, et al. (1999) Morphological study of bone regeneration in the presence of 6-oxychitin. Carbohydrate Polymers 40(1): 23-27.

30. Muzzarelli RAA, Muzzarelli C, Cosani A, Terbojevich M (1999) 6-oxychitins, novel hyaluronan-like regiospecifically carboxylated chitins. Carbohydrate Polymers 39(4): 361-367.

31. O’Toole MG, Henderson RM, Soucy PA, Fasciotto BH, Hoblitzell PJ, et al. (2012) Curcumin encapsulation in sub-micrometer spray-dried chitosan/tween 20 particles. Bio-macromolecules 13(8): 2309-2314. 
32. Nicodemus GD, Bryant SJ (2008) Cell encapsulation in biodegradable hydrogels for tissue engineering applications. Tissue Eng Part B Rev 14(2): 149-165.

33. Priya SG, Jungvid H, Kumar A (2008) Skin tissue engineering for tissue repair and regeneration. Tissue Eng Part B Rev 14(1): 105-118.

34. Tuzlakoglu K, Reis RL (2009) Biodegradable polymeric fibre structures in tissue engineering. Tissue Engineering Part B Rev 15(1): 17-27.
35. Muzzarelli RAA (2009) Chitins and chitosans for the repair of wounded skin, nerve, cartilage and bone. Carbohydrate Polymers 76(2): 167-182.

36. Li Q Yang D, Ma G, Xu Q Chen X, et al. (2009) Synthesis and characterization of chitosan-based hydrogels. International Journal of Biological Macromolecules 44(2): 121-127.

For possible submissions Click below: 